\title{
SWAT-based hydrological modelling of tropical land-use scenarios
}

\begin{abstract}
The Hulu Langat basin, a strategic watershed in Malaysia, has in recent decades been exposed to extensive changes in land-use and consequently hydrological conditions. In this work, the impact of Land Use and Cover Change (LUCC) on hydrological conditions (water discharge and sediment load) of the basin were investigated using the Soil and Water Assessment Tool (SWAT). Four land-use scenarios were defined for land-use change impact analysis, i.e. past, present (baseline), future and water conservation planning. The land-use maps, dated 1984, 1990, 1997 and 2002, were defined as the past scenarios for LUCC impact analysis. The present scenario was defined based on the 2006 land-use map. The 2020 landuse map was simulated using a cellular automata-Markov model and defined as the future scenario. Water conservation scenarios were produced based on guidelines published by Malaysiâ̂ Department of Town and Country Planning and Department of Environment. Model calibration and uncertainty analysis was performed using the Sequential Uncertainty Fitting (SUFI-2) algorithm. The model robustness for water discharge simulation for the period 1997 ï 2008 was good. However, due to uncertainties, mainly resulting from intense urban development in the basin, its robustness for sediment load simulation was only acceptable for the calibration period 1997ï 2004. The optimized model was run using different land-use maps over the periods 1997ï 2008 and 1997ï 2004 for water discharge and sediment load estimation, respectively. In comparison to the baseline scenario, SWAT simulation using the past and conservative scenarios showed significant reduction in monthly direct runoff and monthly sediment load, while SWAT simulation based on the future scenario showed significant increase in monthly direct runoff, monthly sediment load and groundwater recharge.
\end{abstract}

Keyword: LUCC; SWAT; Calibration; Uncertainty analysis; Hulu Langat basin; Malaysia 